\title{
Endocrine Responses to Sport-Related Brain Injury in Female Athletes: A Narrative Review and a Call for Action
}

\author{
Donna Duffy ${ }^{1, *}$, Kirsty J. Elliott-Sale ${ }^{2}$, , Hanna Gardner ${ }^{3}$, Samantha Goldenstein ${ }^{3}$ and Laurie Wideman ${ }^{3}(\mathbb{D})$ \\ 1 Center for Women's Health and Wellness University of North Carolina at Greensboro, \\ Greensboro, NC 27412, USA \\ 2 Musculoskeletal Physiology Research Group, Sport Health and Performance Enhancement Research Centre, \\ Nottingham Trent University, Nottingham NG11 8NS, UK; kirsty.elliottsale@ntu.ac.uk \\ 3 Department of Kinesiology, University of North Carolina at Greensboro, Greensboro, NC 27412, USA; \\ hmgardne@uncg.edu (H.G.); sjgolden@uncg.edu (S.G.); 1_widema@uncg.edu (L.W.) \\ * Correspondence: dmduffy@uncg.edu
}

Citation: Duffy, D.; Elliott-Sale, K.J.; Gardner, H.; Goldenstein, S.;

Wideman, L. Endocrine Responses to Sport-Related Brain Injury in Female Athletes: A Narrative Review and a Call for Action. Endocrines 2021, 2, 99-108. https://doi.org/10.3390/ endocrines 2020010

Academic Editor: Paolo Sgrò

Received: 27 March 2021

Accepted: 19 April 2021

Published: 23 April 2021

Publisher's Note: MDPI stays neutral with regard to jurisdictional claims in published maps and institutional affiliations.

Copyright: (c) 2021 by the authors. Licensee MDPI, Basel, Switzerland. This article is an open access article distributed under the terms and conditions of the Creative Commons Attribution (CC BY) license (https:// creativecommons.org/licenses/by/ $4.0 /)$.

\begin{abstract}
Sport-related brain injury (SRBI) occurs when a blow to the head causes the brain to move back and forth in the skull, and can lead to neuroendocrine dysfunction. Research has shown that males and females experience and recover from SRBI differently, yet most of what is known regarding diagnosis, treatment, and recovery of SRBI is based on male normative data even though females meet or exceed incidence numbers of SRBIs compared to those of males. Females also have been known to have worse outcomes and a greater number of symptoms following SRBI than males. Research is limited as to why females have worse outcomes, but sex hormones have been suggested as a potential reason. SRBI may cause a dysregulation of the hypothalamic-pituitary-gonadal (HPG) axis, which is responsible for regulating the sex hormones estrogen and progesterone. Initial research has shown that SRBI may suppress estrogen and progesterone, and the concentration of these sex hormones could be indicative of injury severity and recovery trajectory. This review discusses the sex-specific differences in SRBI and also the future direction of research that is needed in order to identify the repercussions of SRBIs for female athletes, which will eventually lead to better clinical treatment, sideline care, and recovery profiles.
\end{abstract}

Keywords: sport-related brain injury; estrogen; progesterone; menstrual cycle; hypopituitarism

\section{Introduction}

Since the passage of Title IX in 1972, female sport participation has steadily increased in the United States. The passage of Title IX mandated, among other things, equal sport opportunities for females. While this did not lead to equal numbers of males and females playing all sports, female athlete participation in high-contact and collision sports that were historically limited to male athletes, such as ice hockey, rugby, and tackle football [1,2] has increased-and by extension, the number of sport injuries in female athletes has also increased, including sport-related brain injury (SRBI). Traditionally, it was assumed that female athletes were less likely to experience SRBIs because their sport participation was perceived to be less physical. Recent data suggests that the rate of SRBIs in female athletes meets or exceeds those of male athletes, in sports where both sexes participate [3-6].

SRBIs are caused by a blow to the head or the body, causing the brain to move back and forth in the skull, resulting in a neurochemical response that activates different parts of the brain (e.g., originating in the hypothalamus and pituitary gland) to respond to the sustained trauma [7-9]. The research regarding the complexities of how the hypothalamus and the pituitary gland react to SRBI is in its infancy. Researchers currently speculate that disruptions in the hypothalamus and the pituitary gland may result in hypopituitarism. Hypopituitarism is defined as a deficiency of one or more pituitary-based hormones (e.g., estrogen and/or progesterone) [10]. Depending on the severity and magnitude of the SRBI, 
hypopituitarism can cause a withdrawal of hormones such as estrogen and progesterone, resulting in neuroendocrine dysfunction [11-13]. Neuroendocrine dysfunction is characterized by ill-timed hormonal signaling and output, which can impact the timing and patterns of the menstrual cycle, among other things [11-13]. Over the past two decades SRBI has received a lot of attention and resources in both the research and clinical realms. Most of what is known regarding the diagnosis and treatment of, and recovery from SRBI is based on male normative values, which is problematic given that males and females experience and recover from SRBI differently $[6,14,15]$.

\section{The Need for Sex-Specific Brain Injury Research}

Clinical studies have shown that there are sex-based differences at the genetic, cellular, and physiological levels between males and females [16]. Despite this, numerous studies [17-19] have reported poor levels of inclusion of female populations in medical research. In 2016, an Institute of Medicine report showed that females made up less than $40 \%$ of research study populations. This study further reported that when considering animal research — typically used as the basis for designing and implementing human studies—only $22-40 \%$ reported sex as a variable. In addition, females are still severely underrepresented in sport and exercise medicine research, making up only 39\% of research participants [16]. Disparities in the inclusion of females and in the reporting of sex-specific outcomes have resulted in a significant gap in scientific knowledge and clinical application regarding female health outcomes, especially within the sports realm. Data now indicates that this is not the case, as female experiences with SRBIs are vastly different from their male counterparts [20-23]. While data from males can provide guidance and insight into potential pathophysiological pathways for pursuit, researching biological distinctions between the sexes or pathophysiological pathways distinct to females (i.e., the menstrual cycle), can contribute a more nuanced and fine-grained approach to research focused on SRBI, and as a result, more appropriate sex-specific clinical care. Recently, the examination and inclusion of biological sex has been emphasized in research design to better understand the extent to which sex modifies, or influences, the nature and course of recovery following an injury, including a SRBI $[22,24,25]$. Biological sex refers to the set of biological attributes in females and males associated with gene expression, hormone function and chromosomes. The National Institutes of Health (NIH) has recently identified sex as a biological variable (SABV) as a factor that may influence the incidence, progression, and outcome in research and clinical care [26]. NIH's policy on including SABV in research was implemented since it has become clear that sex differences need to be researched so that appropriate steps to establish clinical care for distinctive populations can be realized. Medical and/or biological research outcomes that are considered "gender neutral" and/or are skewed to male biological outcomes, is a missed opportunity to create more appropriate, sex-specific, diagnostics and treatment approaches that benefit the unique biological make up of females.

\section{Sex-Specific Differences in SRBI}

The World Health Organization (WHO) estimates that 69 million people will suffer from a brain injury each year and of those, about 3.8 million injuries will be sustained through sport/physical activity/recreation participation. The causes of SRBI vary based on geographical, environmental, biological, and cultural factors. A 2020 report by the American Academy of Orthopedic Surgeons revealed that despite the increased awareness among coaches and other stakeholders, efforts to prevent/reduce SRBI have not been fully realized, and incidences of SRBI continue to rise. Although data are scarce, the existing literature suggests that the rates of female SRBI are at least as high as those in male athletes when considering sports where both sexes participate [3-6], indicating that SRBI is a health concern for both female and male athletes. Furthermore, research also suggests that female athletes may have worse outcomes than male athletes following a SRBI, as they report a greater number of symptoms $[20,27,28]$, have higher symptom scores [29], more severe cognitive declines [28], and are more likely to experience a prolonged recovery [25,30-32]. 
Collectively, this research indicates that SRBI does not lead to homogenous outcomes for males and females, and research investigating factors associated with sexually dimorphic outcomes following SRBIs is needed.

In 2016, Dr. Brian Hainline, Medical Director of the NCAA said, "Understanding of the reasons for differences in SRBI between the sexes is poor." Consensus statements and position papers concerning SRBIs have been published highlighting the importance of considering sex differences, preinjury characteristics, and injury-specific variables as possible modifiers of SRBI outcomes [26,33-35]. Given the increased prevalence of SRBI and potentially higher levels of symptom reporting among females, research that informs how biological sex influences the outcomes following SRBI is critical. While numerous studies on SRBI have compared the outcomes of male and female athletes, research pertaining to why female athletes have worse outcomes is limited. To date, only a small body of research $[6,27,36]$ has examined potential mechanisms that may contribute to sex differences in outcomes following SRBI. Biomechanical mechanisms, related to sex differences in 'neck strength to head size' ratio that make it more challenging for females to stabilize their head and neck during a head acceleration, have been proposed [37]. Socio-cultural influences, related to gender socialization in sport whereby female athletes may be more willing to report SRBI and the severity of symptoms, have also been suggested [6,38]. A novel line of research, with a growing body of evidence $[29,39,40]$ suggests that female sex hormones may also influence a female athlete's experience with SRBI, further supporting the need for sex-specific research for this topic.

\section{Hypopituitarism}

Case reports have been published documenting endocrine dysfunction after a traumatic brain injury (TBI), which is different from SRBI. A TBI occurs from sudden, violent trauma (i.e., a car accident), which can cause immediate, life-altering diminished brain function. SRBI are a type of TBI and are sometimes referred to as mild TBI (mTBI) and are often considered much less severe in terms of symptoms and recovery time. Research has recently demonstrated endocrine disruption as a result of external mechanisms that cause the brain to respond and react inside the skull to an outside force (e.g., a ball to the head). Endocrine disruption can take on many forms, but one of the most common forms is hypopituitarism-deficiency of one or more hormones produced and regulated in the pituitary gland, which can be acute or chronic in nature [10]. The pituitary gland is often referred to as the "master gland," because the hormones it produces act as the chemical regulator for hormone production in other glands [41]. The pituitary gland is roughly the size of a pea and is divided into two sections: the anterior and posterior. Both sections of the pituitary gland are connected to the hypothalamus through a stalk of blood vessels and nerves. Through the stalk, the hypothalamus chemically communicates with the anterior section of the pituitary gland via hormones, and through the posterior section via nerve impulses [41].

Hypopituitarism may develop in a female athlete after a single blow to the head or body or after multiple, repetitive SRBIs. Some research suggests that the likelihood of developing hypopituitarism after SRBI depends on the severity of the sustained head trauma, hormone levels at the time of injury, as well as possible genetic influences [42-46]. When SRBI are experienced by a female athlete, disruptive changes to cerebral blood flow can lead to an overproduction and secretion of hormones in the pituitary gland, resulting in a cascade of neuroendocrine dysfunction (NED) $[47,48]$. NED is an indication of hormonal imbalances and dysregulation that can affect numerous axes related to the hypothalamicpituitary connection, but in relation to female athletes, the hypothalamic-pituitary-gonadal (HPG) axis is of specific interest. The HPG axis is responsible for communicating and regulating the activities at the intersection of the reproductive and endocrine systems. In females, the specific topic of interest is the regulation and secretion of the female sex hormones-estrogen and progesterone [40,44,49,50]. 
Both estrogen and progesterone are primarily responsible for regulating the female reproductive system, including the menstrual cycle, and both originate in the hypothalamicpituitary-gonadal axis (HPG axis). Environment (e.g., SRBI) can have a major impact on the function of the pituitary gland, and by extension the HPG axis, which can disrupt the regulation and secretion of estrogen and progesterone, negatively affecting the menstrual cycle [40,51-53]. The relations between SRBI and estrogen and progesterone appear to be bidirectional; SRBI often leads to the suppression/alteration of estrogen and progesterone, and the concentration of estrogen and progesterone at the time of the SRBI can be indicative of the injury severity and recovery trajectory [54]. Since males and females naturally have different concentrations of sex hormones, with females having higher concentrations of estrogen and progesterone and males having higher concentrations of testosterone, any disruption related to the production of these hormones will have different implications for males and females. Therefore, it can be hypothesized that hormonal deficiencies as a result of SRBI in females and males are likely to have variable, but significant, effects on brain function [55].

To date, there are no diagnostic processes or well-established algorithms to screen for hypopituitarism in female athletes when a SRBI is experienced. This is problematic since recent research has suggested that hypopituitarism after SRBI may be more common than once thought and that anterior hypopituitarism is likely to be seen in approximately $25 \%$ of female athletes with SRBI [56]. These reduced hormonal outputs from the pituitary gland are likely to lead to a sequela of neuroendocrine dysfunction, since other glands (i.e., thyroid, adrenal) and organs (i.e., gonads) that rely on hormones secreted from the pituitary gland will also be disrupted $[53,56]$.

The production of a normal menstrual cycle in females of child-bearing age relies on the integration of numerous hormones. In a metronome-like fashion, the hypothalamus controls the pattern of the menstrual cycle with the pulsatile release of gonadotropinreleasing hormone $(\mathrm{GnRH})$, which stimulates the pituitary to secrete luteinizing hormone (LH) and follicle-stimulating hormone (FSH). GnRH is both necessary and sufficient to drive the menstrual cycle [57]. In practical terms, the pituitary gland translates the pattern set by the hypothalamus into a hormonal signal (LH and FSH) that the ovary understandsresponding with the production of estrogen and progesterone in varying amounts across the menstrual cycle [57]. Estrogen and progesterone are produced through key steroidogenic pathways in the ovary [57] and are critical for female reproductive health and proper menstrual cycle function in adulthood, but they also contribute to female growth and development in adolescence and influence bone health, body temperature, cholesterol production, and nervous system regulation [58-61]. Circulating estrogen and progesterone feed back to the hypothalamus and pituitary to help control GnRH, LH, and FSH output, thus providing critical input for normal menstrual cycle function. Given this extraordinarily intricate system, hypopituitarism secondary to SRBI in females is likely to have widespread effects on menstrual cycle function and ultimately, if the NED is significant, reproductive health will also be affected.

\section{Progesterone}

The steroid hormone progesterone belongs to the progestogens. It is mainly secreted by the corpus luteum in the ovary during the second half of the menstrual cycle. Several studies have shown that following SRBI the HPG axis is suppressed, leading to a decrease in progesterone concentrations [56,62]. Therefore, it appears that, in the wake of SRBI, a cascade of NED may occur that suddenly decreases the amount of progesterone. Regardless of menstrual cycle phase, progesterone is normally present in higher concentrations in the female brain compared to males [63]. Consequently, males experience a less rapid and overall lower magnitude of progesterone withdrawal following SRBI and overall, appear less affected by the suppression of the HPG axis and the withdrawal of progesterone, compared to females $[40,48]$. The rapid withdrawal of progesterone experienced by females following SRBI may partially explain the less optimal clinical outcomes for 
females compared to males following SRBI. Furthermore, since progesterone is a critical sex hormone for regulating female reproductive health and the menstrual cycle, SRBI have significant repercussions for female brain and reproductive health [40].

\section{Estrogen}

Estrogen is secreted by the ovaries in large quantities [57]. Following SRBI, the pituitary gland may not produce sufficient amounts of LH and FSH, ultimately altering the production of estrogen [64]. This reduction in estrogen can lead to subsequent reductions in the stress response, as well as diminished cognitive function [65]. As with progesterone, the effects of this reduction in estrogen following SRBI appear to be different between males and females [45]. Sex differences in estrogen concentration levels pre- and post- SRBI, may therefore have implications for outcomes following head injuries in females [29,66]. As with progesterone, the rapid and significant alterations in estrogen output that could occur as a downstream outcome of hypopituitarism and NED is under-researched and the functional consequences are poorly understood [11,29]. Determining the impact of SRBI on the regulation of estrogen is an important step in examining and determining the shortand long-term consequences of how SRBI in female athletes differs from how it presents in their male counterparts. Equally importantly, it is unclear whether SRBI alters the number or function of estrogen or progesterone receptors in the brain-a further complication that could significantly alter the menstrual cycle and reproductive health.

\section{SRBI and the Menstrual Cycle}

Estrogen and progesterone vary across the menstrual cycle, and these fluctuations have been suggested to be a factor in the onset of and recovery from SRBI seen between the sexes [11,29]. Specifically, estrogen levels are low at the beginning of the cycle (i.e., during menstruation) and then peak prior to ovulation. If an SRBI occurs near the peak of estrogen, the head trauma may lead to a sudden decrease in estrogen concentration $[51,53]$. This sudden withdrawal of estrogen can lead to negative outcomes with respect to SRBI symptoms and recovery in females $[29,51,53]$. The menstrual cycle and the hormonal profiles that sustain it are not experienced by men, potentially explaining sex-related differences after head trauma. Progesterone is low throughout the follicular and ovulatory phases of the menstrual cycle and then begins to rise during the luteal phase. It peaks in the middle of the luteal phase, so SRBI sustained during this time can lead to an acute decrease in progesterone and negative SRBI-related outcomes [29,51,53]. Wunderle et al. (2014) showed that menstrual phase impacted SRBI symptoms and quality of life health scores, with those injured during the luteal phase of the menstrual cycle proving worse affected than females injured during the follicular phase or females taking oral contraceptives (i.e., as oral contraceptive users have downregulated levels of estrogen and progesterone). Since the luteal phase is the time of the highest progesterone levels, these results support the "withdrawal hypothesis", which describes SRBI occurring in settings of high progesterone resulting in sudden decreases-leading to worse outcomes than SRBI occurring in settings of low progesterone [40]. Thus, it is plausible that SRBI that occur during the ovulatory phase (due to the peak of estrogen) or in the middle of the luteal phase (due to the peak of progesterone) could lead to similar negative outcomes. Ripley (2008) found that $90 \%$ of females reported missing periods within the year following brain injury, compared to just $23 \%$ prior to injury, indicating neuroendocrine dysfunction and likely alterations in the levels of estrogen and progesterone. Severity of SRBI was significantly predictive of longer durations of amenorrhea, and shorter durations of amenorrhea were predictive of better outcomes and return to healthy life [62].

\section{Future Directions: A Call to Action}

Research has demonstrated that female athletes meet or exceed incidence numbers of SRBIs compared to those of their male counterparts, although the research to date has focused primarily on male athletes, resulting in a dearth of understanding and clinical 
treatment centered on female athlete symptomology and recovery from SRBIs. Historically, females were not included in SRBI research because it was believed that females did not participate in sports where SRBIs were a possible outcome. Given the vast unknown acute and chronic outcomes of SRBIs in female athletes, as well as the growing numbers of female athletes in all sports, including ones that were once reserved solely for males, it is no longer acceptable to exclude female athletes in research designs.

We have identified future research directions that would provide important scientific insight into the repercussions of SRBIs for female athletes, which will eventually lead to better clinical treatment, sideline care, and recovery profiles for SRBI in female athletes.

1. Repetitive head trauma, sometimes referred to as sub-concussive trauma, needs to be examined in female athletes in both the short and long term. Repetitive head trauma (or sub-concussive head trauma) does not result in diagnosable symptoms (i.e., dizziness, imbalance), making it extremely difficult to detect and diagnose. Researchers believe that longitudinal, repetitive head trauma can have serious, detrimental effects on physical and cognitive health [67-70]. Stern and colleagues at Boston University are extensively studying repetitive head trauma (sub-concussive trauma) in former male National Football League (NFL) players and have determined that repetitive head trauma from sport participation is a risk factor for later life neurocognitive and neuropsychiatric disease [67-70]. In the United States and around the world, female athletes are participating in sports where repetitive head trauma is a part of the sporting environment. Currently, in the United States, it is estimated that there are around 4000 female tackle football players, participating in two different leagues, where one league has a 10+ year participation history. The female tackle football players play by a mix of NFL and National Collegiate Athletic Association (NCAA) rules. Often, we are asked by female football players, "If I continue to play, will have the same issues as the former NFL players?", to which we answer, "We do not know. Yet. We do not yet know if we will see the same prevalence and severity of head injuries in female football players as have previously been seen in the NFL."

2. Some research $[11,12]$ suggests that there are immediate endocrine-based responses when a female athlete experiences a SRBI. In this review, we identified this concept as NED. Given the vast responsibilities of the pituitary gland and hypothalamus in the production and regulation of female sex hormones, it is critical that future research examines the acute changes in female sex hormones in response to SRBI. While this review has focused on estrogen and progesterone, it is critical to point out that there are several other important HPG axis hormones that are vital for the maintenance of proper menstrual cycle function and reproductive health (i.e., GnRH, LH, FSH) and little to no research exists on these other hormones. Thus, the menstrual cycle should be considered a vital sign for females [71] and abrupt changes in menstrual cycle function should never be ignored in female athletes.

3. The ability to identify novel biomarkers that could be used to detect and/or diagnose pituitary hormone deficiencies that occur in the acute phase following SRBI requires studies to elucidate the nuanced changes that occur in both structure and function of various brain regions and the hormonal alterations that result from these changes. These novel biomarkers may also help to determine the time course of hormonal deficiencies that develop as the brain transitions from the acute to the chronic phase of SRBI. Ultimately, the culmination of these efforts would inform better rehabilitation and recovery interventions for female athletes.

4. Longitudinal research is critical for understanding the chronic outcomes related to SRBI in female athletes. What we know about chronic outcomes for SRBI is based solely on the experiences of male athletes, specifically former NFL players and boxers, which is problematic given the sex-based differences outlined in this article. Therefore, it is critical that future research efforts not only track head injury exposure, but also the long-term physiological and psychological outcomes of such head injuries, which are likely to impact quality of life in these female athletes. 
5. Even though it is "messy," the menstrual cycle must be accounted for in biologically based female athlete research. Research has highlighted that a SRBI disrupts the menstrual cycle and can lead to irregular menstrual cycles. Importantly, irregular menstruation can lead to an increased risk for chronic disease and premature mortality among females. Although the first steps forward in this relatively new area of research requires assessment of clinically overt impacts on menstrual cycle function, it is critical to point out that many disruptions in 'normative' menstrual cycle function are not clinically observable. For instance, normative menstrual cycles (i.e., occurring every 26-32 days), are not necessarily indicative of ovulatory cycles. Equally important is the notion that luteal phase defects can result in reproductive issues even when ovulatory cycles occur [72]. Nuanced changes in sex-steroid profiles over time may not produce overt menstrual cycle disruptions and thus, seemingly normal variations may obfuscate underlying reproductive issues.

6. Given the acute, immediate hormonal response that occurs when a female athlete experiences a brain injury, future research should investigate how the hormonal response to brain injury may cause, contribute to, mask, or exacerbate other femalerelated performance disorders (i.e., the Female Athlete Triad, REDS).

\section{Conclusions}

In summary, sport participation impacts multiple facets of wellbeing in female athletes and while it occurs most often during the early stages of the life span (i.e., reproductive years), the outcomes of sport participation may have lifelong consequences, both positive and negative.

Author Contributions: Conceptualization, D.D., K.J.E.-S., L.W.; methodology, D.D.; investigation, D.D., K.J.E.-S., H.G., S.G., L.W.; writing—original draft preparation, D.D.; writing—review and editing, D.D., K.J.E.-S., H.G., S.G., L.W.; visualization, S.G.; supervision, D.D.; project administration, D.D. All authors have read and agreed to the published version of the manuscript.

Funding: This research received no external funding.

Institutional Review Board Statement: Not applicable.

Informed Consent Statement: Not applicable.

Data Availability Statement: Not applicable

Acknowledgments: The authors would like to thank Travis Anderson for his input and insight into this paper.

Conflicts of Interest: The authors declare no conflict of interest.

\section{References}

1. National Federation of State High School Associations High School Athletics Participation Survey 2018-19. Available online: https:/ / www.nfhs.org/media/1020412/2018-19_participation_survey.pdf (accessed on 25 March 2021).

2. National College Athletic Association Sports Sponsorship and Particpation Rates Report 2018. Available online: https:// ncaaorg.s3.amazonaws.com/research/sportpart/Oct2018RES_201718SportsSponsorshipParticipationRatesReport.pdf (accessed on 25 March 2021).

3. Gessel, L.M.; Fields, S.K.; Collins, C.L.; Dick, R.W.; Comstock, R.D. Concussions Among United States High School and Collegiate Athletes. J. Athl. Train. 2007, 42, 495-503.

4. Zuckerman, S.L.; Kerr, Z.Y.; Yengo-Kahn, A.; Wasserman, E.; Covassin, T.; Solomon, G.S. Epidemiology of Sports-Related Concussion in NCAA Athletes From 2009-2010 to 2013-2014: Incidence, Recurrence, and Mechanisms. Am. J. Sports Med. 2015, 43, 2654-2662. [CrossRef] [PubMed]

5. Covassin, T.; Swanik, C.B.; Sachs, M.L. Sex Differences and the Incidence of Concussions Among Collegiate Athletes. J. Athl. Train. 2003, 38, 238-244.

6. Dick, R.W. Is There a Gender Difference in Concussion Incidence and Outcomes? Br. J. Sports Med. 2009, 43, i46-i50. [CrossRef]

7. Abdelmalik, P.A.; Draghic, N.; Ling, G.S.F. Management of Moderate and Severe Traumatic Brain Injury. Transfusion 2019, 59, 1529-1538. [CrossRef]

8. Woolf, P.D. Hormonal Responses to Trauma. Crit. Care Med. 1992, 20, 216-226. [CrossRef]

9. Center for Disease Control and Prevention (CDC). Available online: www.cdc.gov (accessed on 25 March 2021). 
10. Heidelbaugh, J. Endocrinology Update: Hypopituitarism. FP Essent. 2016, 451, 25-30.

11. Di Battista, A.P.; Rhind, S.G.; Churchill, N.; Richards, D.; Lawrence, D.W.; Hutchison, M.G. Peripheral Blood Neuroendocrine Hormones Are Associated with Clinical Indices of Sport-Related Concussion. Sci. Rep. 2019, 9, 18605. [CrossRef]

12. Molaie, A.M.; Maguire, J. Neuroendocrine Abnormalities Following Traumatic Brain Injury: An Important Contributor to Neuropsychiatric Sequelae. Front. Endocrinol. 2018, 9. [CrossRef] [PubMed]

13. Pavlovic, D.; Pekic, S.; Stojanovic, M.; Popovic, V. Traumatic Brain Injury: Neuropathological, Neurocognitive and Neurobehavioral Sequelae. Pituitary 2019, 22, 270-282. [CrossRef] [PubMed]

14. Mollayeva, T.; El-Khechen-Richandi, G.; Colantonio, A. Sex \& Gender Considerations in Concussion Research. Concussion 2018, 3. [CrossRef]

15. Resch, J.; Walton, S.; Broshek, D. Sport Concussion and the Female Athlete-Clinics in Sports Medicine. Clin. Sports Med. 2017, 36, 717-739. [CrossRef] [PubMed]

16. Costello, J.T.; Bieuzen, F.; Bleakley, C.M. Where Are All the Female Participants in Sports and Exercise Medicine Research? Eur. J. Sport Sci. 2014, 14, 847-851. [CrossRef]

17. Feuerstein, I.M.; Jenkins, M.R.; Kornstein, S.G.; Lauer, M.S.; Scott, P.E.; Raju, T.N.K.; Johnson, T.; Devaney, S.; Lolic, M.; Henderson, M.; et al. Working Together to Address Women's Health in Research and Drug Development: Summary of the 2017 Women's Health Congress Preconference Symposium. J. Women's Health 2018, 27, 1195-1203. [CrossRef] [PubMed]

18. Liu, K.A.; DiPietro Mager, N.A. Women's Involvement in Clinical Trials: Historical Perspective and Future Implications. Pharm. Pract. 2016, 14, 708. [CrossRef]

19. Mazure, C.M.; Jones, D.P. Twenty Years and Still Counting: Including Women as Participants and Studying Sex and Gender in Biomedical Research. BMC Women's Health 2015, 15, 94. [CrossRef] [PubMed]

20. Covassin, T.; Elbin, R.; Lipchik, A.; Kontos, A.P. Are There Differences in Neurocognitive Function and Symptoms Between Male and Female Soccer Players After Concussions? Am. J. Sports Med. 2013, 41, 2890-2895. [CrossRef] [PubMed]

21. Cheng, J.; Ammerman, B.; Santiago, K.; Jivanelli, B.; Lin, E.; Casey, E.; Ling, D. Sex-Based Differences in the Incidence of Sports-Related Concussion: Systematic Review and Meta-Analysis. Sports Health 2019, 11, 486-491. [CrossRef]

22. Howell, D.R.; Stracciolini, A.; Geminiani, E.; Meehan, W.P. Dual-Task Gait Differences in Female and Male Adolescents Following Sport-Related Concussion. Gait Posture 2017, 54, 284-289. [CrossRef]

23. Ling, D.I.; Cheng, J.; Santiago, K.; Ammerman, B.; Jivanelli, B.; Hannafin, J.; Casey, E. Women Are at Higher Risk for Concussions Due to Ball or Equipment Contact in Soccer and Lacrosse. Clin. Orthop. Relat. Res. 2020, 478, 1469-1479. [CrossRef]

24. Shansky, R.M.; Woolley, C.S. Considering Sex as a Biological Variable Will Be Valuable for Neuroscience Research. J. Neurosci. 2016, 36, 11817-11822. [CrossRef]

25. Miller, L.R.; Marks, C.; Becker, J.B.; Hurn, P.D.; Chen, W.-J.; Woodruff, T.; McCarthy, M.M.; Sohrabji, F.; Schiebinger, L.; Wetherington, C.L.; et al. Considering Sex as a Biological Variable in Preclinical Research. FASEB J. 2017, 31, 29-34. [CrossRef]

26. Clayton, J.A. Applying the New SABV (Sex as a Biological Variable) Policy to Research and Clinical Care. Physiol. Behav. 2018, 187, 2-5. [CrossRef] [PubMed]

27. Merritt, V.; Padgett, C.; Jak, A. A Systematic Review of Sex Differences in Concussion Outcome: What Do We Know? Clin. Neuropsychol. 2019, 33, 1016-1043. [CrossRef] [PubMed]

28. Broshek, D.K.; Kaushik, T.; Freeman, J.R.; Erlanger, D.; Webbe, F.; Barth, J.T. Sex Differences in Outcome Following Sports-Related Concussion. J. Neurosurg. 2005, 102, 856-863. [CrossRef]

29. Bazarian, J.J.; Blyth, B.; Mookerjee, S.; He, H.; McDermott, M.P. Sex Differences in Outcome after Mild Traumatic Brain Injury. J. Neurotrauma 2010, 27, 527-539. [CrossRef]

30. Iverson, G.L.; Gardner, A.J.; Terry, D.P.; Ponsford, J.L.; Sills, A.K.; Broshek, D.K.; Solomon, G.S. Predictors of Clinical Recovery from Concussion: A Systematic Review. Br. J. Sports Med. 2017, 51, 941-948. [CrossRef]

31. Kostyun, R.O.; Hafeez, I. Protracted Recovery From a Concussion: A Focus on Gender and Treatment Interventions in an Adolescent Population. Sports Health 2015, 7, 52-57. [CrossRef]

32. Scopaz, K.A.; Hatzenbuehler, J.R. Risk Modifiers for Concussion and Prolonged Recovery. Sports Health 2013 , 5, 537-541. [CrossRef] [PubMed]

33. Harmon, K.G.; Drezner, J.A.; Gammons, M.; Guskiewicz, K.M.; Halstead, M.; Herring, S.A.; Kutcher, J.S.; Pana, A.; Putukian, M.; Roberts, W.O. American Medical Society for Sports Medicine Position Statement: Concussion in Sport. Br. J. Sports Med. 2013, 47, 15-26. [CrossRef]

34. McCrory, P.; Meeuwisse, W.; Dvořák, J.; Aubry, M.; Bailes, J.; Broglio, S.; Cantu, R.C.; Cassidy, D.; Echemendia, R.J.; Castellani, R.J.; et al. Consensus Statement on Concussion in Sport-the 5th International Conference on Concussion in Sport Held in Berlin, October 2016. Br. J. Sports Med. 2017, 51, 838-847. [CrossRef] [PubMed]

35. Marshall, C.M. Sports-Related Concussion: A Narrative Review of the Literature. J. Can. Chiropr. Assoc. $2012,56,299$.

36. Solomito, M.J.; Reuman, H.; Wang, D.H. Sex Differences in Concussion: A Review of Brain Anatomy, Function, and Biomechanical Response to Impact. Brain Inj. 2019, 33, 105-110. [CrossRef]

37. Tierney, R.T.; Sitler, M.R.; Swanik, C.B.; Swanik, K.A.; Higgins, M.; Torg, J. Gender Differences in Head-Neck Segment Dynamic Stabilization during Head Acceleration. Med. Sci. Sports Exerc. 2005, 37, 272-279. [CrossRef] [PubMed]

38. Wallace, J.; Covassin, T.; Beidler, E. Sex Differences in High School Athletes' Knowledge of Sport-Related Concussion Symptoms and Reporting Behaviors. J. Athl. Train. 2017, 52, 682-688. [CrossRef] [PubMed] 
39. Greco, T.; Ferguson, L.; Giza, C.; Prins, M.L. Mechanisms Underlying Vulnerabilities after Repeat Mild Traumatic Brain Injuries. Exp. Neurol. 2019, 317, 206-213. [CrossRef] [PubMed]

40. Wunderle, M.K.; Hoeger, K.M.; Wasserman, M.E.; Bazarian, J.J. Menstrual Phase as Predictor of Outcome after Mild Traumatic Brain Injury in Women. J. Head Trauma Rehabil. 2014, 29, E1-E8. [CrossRef]

41. Dorton, A. The Pituitary Gland: Embryology, Physiology, and Pathophysiology. Neonatal. Netw. 2000, 19, 9-17. [CrossRef] [PubMed]

42. Benvenga, S.; CampennÍ, A.; Ruggeri, R.M.; Trimarchi, F. Hypopituitarism Secondary to Head Trauma. J. Clin. Endocrinol. Metab. 2000, 85, 1353-1361. [CrossRef] [PubMed]

43. Dusick, J.R.; Wang, C.; Cohan, P.; Swerdloff, R.; Kelly, D.F. Chapter 1: Pathophysiology of Hypopituitarism in the Setting of Brain Injury. Pituitary 2012, 15, 2-9. [CrossRef]

44. Tanriverdi, F.; Senyurek, H.; Unluhizarci, K.; Selcuklu, A.; Casanueva, F.F.; Kelestimur, F. High Risk of Hypopituitarism after Traumatic Brain Injury: A Prospective Investigation of Anterior Pituitary Function in the Acute Phase and 12 Months after Trauma. J. Clin. Endocrinol. Metab. 2006, 91, 2105-2111. [CrossRef] [PubMed]

45. Gray, S.; Bilski, T.; Dieudonne, B.; Saeed, S. Hypopituitarism after Traumatic Brain Injury. Cureus 2019, 11, e4163. [CrossRef] [PubMed]

46. Javed, Z.; Qamar, U.; Sathyapalan, T. Pituitary and/or Hypothalamic Dysfunction Following Moderate to Severe Traumatic Brain Injury: Current Perspectives. Indian J. Endocrinol. Metab. 2015, 19, 753-763. [CrossRef]

47. Kaulfers, A.-M.D.; Backeljauw, P.F.; Reifschneider, K.; Blum, S.; Michaud, L.; Weiss, M.; Rose, S.R. Endocrine Dysfunction Following Traumatic Brain Injury in Children. J. Pediatrics 2010, 157, 894-899. [CrossRef]

48. Yang, L.; Guo, Y.; Wen, D.; Yang, L.; Chen, Y.; Zhang, G.; Fan, Z. Bone Fracture Enhances Trauma Brain Injury. Scand. J. Immunol. 2016, 83, 26-32. [CrossRef]

49. Covassin, T.; Elbin, R.J. The Cognitive Effects and Decrements Following Concussion. Open Access J. Sports Med. 2010, 1, 55-61. [CrossRef]

50. DeMayo, F.J.; Zhao, B.; Takamoto, N.; Tsai, S.Y. Mechanisms of Action of Estrogen and Progesterone. Ann. N. Y. Acad. Sci. 2002, 955, 48-59. [CrossRef]

51. Moreno, M.A. New Updates on Concussions in Girls and Menstrual Patterns. JAMA Pediatr. 2017, 171, 924. [CrossRef] [PubMed]

52. Oyola, M.G.; Handa, R.J. Hypothalamic-Pituitary-Adrenal and Hypothalamic-Pituitary-Gonadal Axes: Sex Differences in Regulation of Stress Responsivity. Stress 2017, 20, 476-494. [CrossRef] [PubMed]

53. Snook, M.L.; Henry, L.C.; Sanfilippo, J.S.; Zeleznik, A.J.; Kontos, A.P. Association of Concussion with Abnormal Menstrual Patterns in Adolescent and Young Women. JAMA Pediatr. 2017, 171, 879-886. [CrossRef] [PubMed]

54. Northam, W.T.; Alexander, A.; Carneiro, K. Sport-Related Concussion Preceding Adrenal Insufficiency and Hypopituitarism. Curr. Sports Med. Rep. 2020, 19, 8-10. [CrossRef]

55. Bollerslev, J.; Klibanski, A.; Tritos, N. Traumatic Brain Injury: Effects on the Endocrine System. J. Clin. Endocrinol. Metab. 2013, 98, 27A-28A. [CrossRef]

56. Agha, A.; Thompson, C.J. Anterior Pituitary Dysfunction Following Traumatic Brain Injury (TBI). Clin. Endocrinol. 2006, 64, 481-488. [CrossRef] [PubMed]

57. Barbieri, R.L. The Endocrinology of the Menstrual Cycle. In Human Fertility: Methods and Protocols; Rosenwaks, Z., Wassarman, P.M., Eds.; Springer: New York, NY, USA, 2014; pp. 145-169, ISBN 978-1-4939-0659-8.

58. Charkoudian, N.; Stachenfeld, N.S. Reproductive Hormone Influences on Thermoregulation in Women. In Comprehensive Physiology; American Cancer Society, Ed.; John Wiley \& Sons: Hoboken, NJ, USA, 2014; pp. 793-804, ISBN 978-0-470-65071-4.

59. McEwen, B.S.; Akama, K.T.; Spencer-Segal, J.L.; Milner, T.A.; Waters, E.M. Estrogen Effects on the Brain: Actions beyond the Hypothalamus via Novel Mechanisms. Behav. Neurosci. 2012, 126, 4-16. [CrossRef]

60. Mumford, S.L.; Steiner, A.Z.; Pollack, A.Z.; Perkins, N.J.; Filiberto, A.C.; Albert, P.S.; Mattison, D.R.; Wactawski-Wende, J.; Schisterman, E.F. The Utility of Menstrual Cycle Length as an Indicator of Cumulative Hormonal Exposure. J. Clin. Endocrinol. Metab. 2012, 97, E1871-E1879. [CrossRef] [PubMed]

61. Seifert-Klauss, V.; Prior, J.C. Progesterone and Bone: Actions Promoting Bone Health in Women. J. Osteoporos. 2010, 2010, e845180. [CrossRef] [PubMed]

62. Ripley, D.L.; Harrison-Felix, C.; Sendroy-Terrill, M.; Cusick, C.P.; Dannels-McClure, A.; Morey, C. The Impact of Female Reproductive Function on Outcomes after Traumatic Brain Injury. Arch. Phys. Med. Rehabil. 2008, 89, 1090-1096. [CrossRef]

63. Henderson, V.W. Progesterone and Human Cognition. Climacteric 2018, 21, 333-340. [CrossRef]

64. Tanriverdi, F.; Schneider, H.; Aimaretti, G.; Masel, B.; Casanueva, F.F.; Kelestimur, F. Pituitary Dysfunction After Traumatic Brain Injury: A Clinical and Pathophysiological Approach. Endocr. Rev. 2015, 36, 305-342. [CrossRef]

65. Brotfain, E.; Gruenbaum, S.E.; Boyko, M.; Kutz, R.; Zlotnik, A.; Klein, M. Neuroprotection by Estrogen and Progesterone in Traumatic Brain Injury and Spinal Cord Injury. Curr. Neuropharmacol. 2016, 14, 641-653. [CrossRef]

66. Gallagher, V.; Kramer, N.; Abbott, K.; Alexander, J.; Breiter, H.; Herrold, A.; Lindley, T.; Mjaanes, J.; Reilly, J. The Effects of Sex Differences and Hormonal Contraception on Outcomes after Collegiate Sports-Related Concussion. J. Neurotrauma 2018, 35, 1242-1247. [CrossRef] [PubMed] 
67. Adams, J.W.; Alvarez, V.E.; Mez, J.; Huber, B.R.; Tripodis, Y.; Xia, W.; Meng, G.; Kubilus, C.A.; Cormier, K.; Kiernan, P.T.; et al. Lewy Body Pathology and Chronic Traumatic Encephalopathy Associated with Contact Sports. J. Neuropathol. Exp. Neurol. 2018, 77, 757-768. [CrossRef]

68. Alosco, M.L.; Mez, J.; Kowall, N.W.; Stein, T.D.; Goldstein, L.E.; Cantu, R.C.; Katz, D.I.; Solomon, T.M.; Kiernan, P.T.; Murphy, L.; et al. Cognitive Reserve as a Modifier of Clinical Expression in Chronic Traumatic Encephalopathy: A Preliminary Examination. JNP 2016, 29, 6-12. [CrossRef] [PubMed]

69. Alosco, M.L.; Mez, J.; Kowall, N.W. Age of First Exposure to Tackle Football and Chronic Traumatic Encephalopathy. Ann. Neurol. 2018, 83, 886-901. [CrossRef] [PubMed]

70. Mez, J.; Daneshvar, D.H.; Abdolmohammadi, B.; Chua, A.S.; Alosco, M.L.; Kiernan, P.T.; Evers, L.; Marshall, L.; Martin, B.M.; Palmisano, J.N.; et al. Duration of American Football Play and Chronic Traumatic Encephalopathy. Ann. Neurol. 2020, 87, 116-131. [CrossRef] [PubMed]

71. Hillard, P.J.A. Menstruation in Adolescents: What Do We Know? And What Do We Do with the Information. J. Pediatr. Adolesc. Gynecol. 2014, 27, 309-319. [CrossRef] [PubMed]

72. De Souza, M.J. Menstrual Disturbances in Athletes: A Focus on Luteal Phase Defects. Med. Sci. Sports Exerc. 2003, 35, 1553-1563. [CrossRef] [PubMed] 